The BDJ News section accepts items that include general news, latest research and diary events that interest our readers. Press releases or articles may be edited, and should include a colour photograph if possible. Please direct your correspondence to the News Editor, Arveen Bajaj at the BDJ, The Macmillan Building, 4 Crinan Street, London N19XW or by email to bdj@bda.org

\section{Laser kills oral bacteria}

Photodynamic therapy (PDT) may be an effective treatment for certain bacterial infections of the oral cavity, including some that are resistant to antibiotics, research from the University at Buffalo's School of Dental Medicine has shown. Researchers found that the bacteria S. mutans, as well as fungal organisms of the genus Candida, were highly susceptible to killing with minimal doses of PDT, both in laboratory dishes and on biofilms grown on denture material. The findings were presented at the recent International Association of Dental Research meeting in Orlando, Florida. 'The results of the studies so far, while not completed, may have important implications in the treatment of oral infectious diseases currently confounding the medical and dental community, said Thomas S. Mang, associate professor of oral and maxillofacial surgery and senior author on the study.

'PDT may provide an adjunct to current antibiotic treatment or an alternative where antibiotics no longer are working. This may be vital for patients undergoing cancer therapy, HIV patients who demonstrate resistance to antibiotics and the elderly with persistent oral infections.'

Photodynamic therapy is based on the propensity of certain types of cells or organisms to absorb light-sensitive drugs. This selective retention allows researchers to direct a laser beam into the organism, which activates the drug and kills the organism but does not damage surrounding tissue.

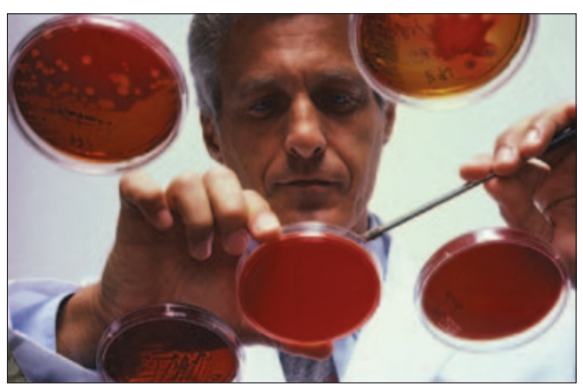

\section{Recognition of salaried dentists}

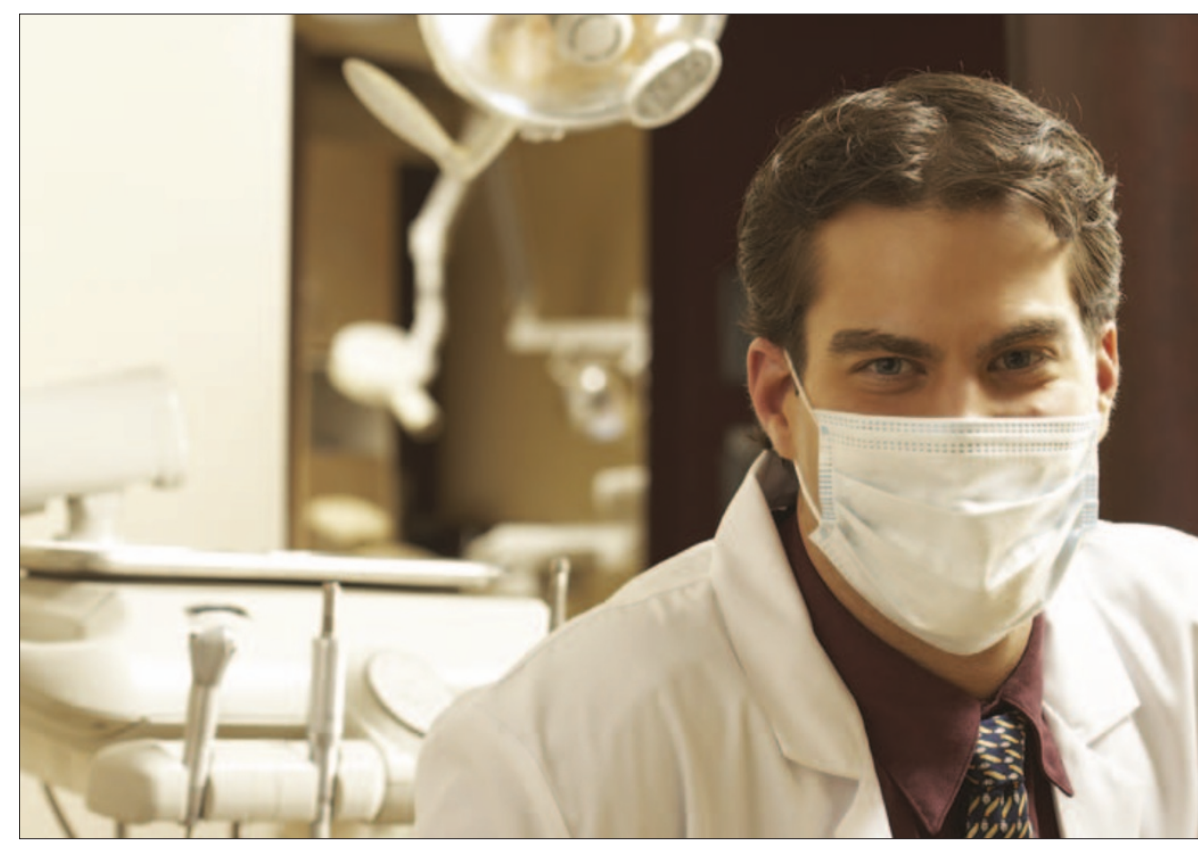

New proposals to encourage career development and increase recognition for NHS salaried dentists in England have been welcomed by the British Dental Association. Following its review of salaried primary dental care services, the Department of Health says it wants to see changes that will modernise careers for salaried dentists, including a new pay spine for salaried generalists and rewarding specialists based in primary care in the same way as their hospital counterparts. In a letter to salaried dentists, Acting Chief Dental Officer Barry Cockcroft says the Department has now asked NHS employers to negotiate with the BDA new terms and conditions for salaried dentists. Acknowledging that concerns have been raised about the future of the salaried services' role in caring for people with special dental needs, the letter also states that the Department will discuss the implications of the General Dental Council's recent decision to approve a new specialty in special care dentistry.

\section{Reporting domestic violence}

Researchers at the University of Kentucky in the US say that with proper training, dental professionals have the opportunity to play a pivotal role in detecting and reporting violence against women. Dentists and dental hygienists may be the first or only health care professional to treat a domestic violence victim. The research team have examined the training needs of dental professionals and created practical curricular materials to help them respond appropriately.

Results of a survey to Kentucky dentists revealed that few have had training in recognition of violence against women, and more than half said that they needed more training in identification and management of domestic violence victims. Collective results indicated that the majority of dentists do not screen for or refer patients who are victims of domestic violence. However, the dentists expressed an interest in and commitment to increased training to improve their ability to respond. 


\section{DIARY}

April

British Society for the Study of Prosthetic Dentistry Annual Conference Venue: Carlton Hotel, Edinburgh Date: 9-11 April 2006

Email: bookings@bsspd.org www.bsspd.org

May

Dental Sedation Teachers' Group

Annual Symposium 2006

Undergraduate Sedation Teaching:

Where are we?

Venue: New Hunts House, Guy's Campus, London SE1 1UL

Date: Tuesday 9 May 2006

Email: carole.boyle@kcl.ac.uk

www.dstg.co.uk

2006 British Dental Conference and Exhibition 'Making it work together'

Venue: International Conference Centre, Birmingham,

Date: 18-20 May

telephone 08701666625

www.bda-events.org

Annual Lillian Lindsay Memorial Lecture and British Dental Association Conference

Venue: Executive Room 1, International Convention Centre, Birmingham

Date: 20 May at $2.30 \mathrm{pm}$

Entrance is free

June

10th European Congress Dentomaxillofacial Radiology

Venue: Provinciehuis

Leuven, Belgium

Date: 31 May-2 June 2006

www.10ecdmfr.be

3M ESPE Seminar

Successful Crown and Bridge Restoration Date: Saturday, 24 June 2006

Venue: Chancellors Hotel \&t Conference

Centre, Chancellors Way, Moseley Road,

Manchester M14 6NN

July

82nd Congress of the European Orthodontic Society

Venue: Hofburg Congress Center

Vienna, Austria

Date: 4-8 July 2006

Tel. (+43/1) 53116 - 38

Fax: (+43/1) $53116-61$

e-mail: azmedinfo@media.co.at

\section{BDA/Dentsply Student Clinician Awards}

The 29th annual Student Clinician Programme Awards Ceremony was held at The Savoy Hotel, London on 3 February 2006. First place went to Prashant Naik, a Barts and The London School of Medicine and Dentistry student who presented 'The Role Of InsulinLike Growth Factor 1 and Its Receptor In Oral Cancer'. Maxine Furley, a student from the School of Dentistry, Newcastle University won second place. Her presentation was called 'Risk Factors and Clinical Outcome Following Laser Surgery in Pre-Oral Cancer Patients'. University of Cork School of Dentistry student Thomas Barry won third place with a presentation entitled Make it Legal and We'll All Be Smiling. Thomas was also awarded the Adjudicators' prize for Professionalism and Presentation.

The BDA/Dentsply Student Clinician Awards programme supports international undergraduate study and highlights the continuous bond that exists between the profession and the dental industry. The programme focuses on original research.

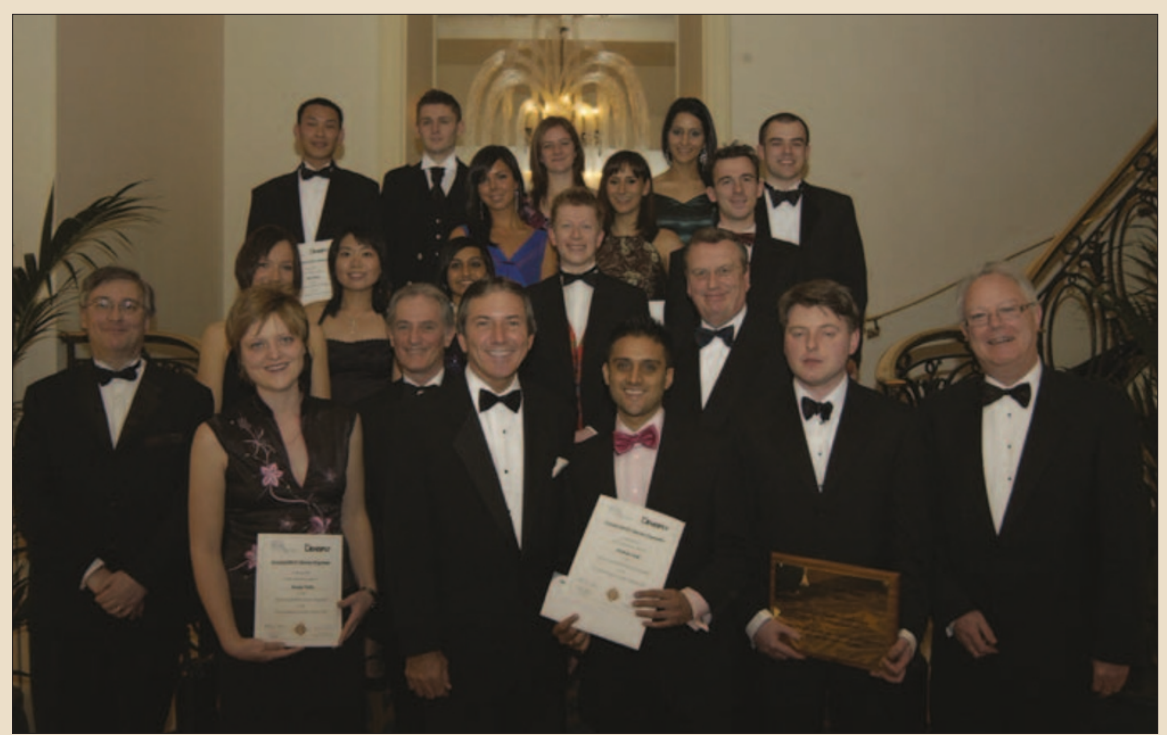

Prashant Naik, centre, collects his award

\section{GDC to introduce changes to the International Qualifying Examination}

The GDC is examining a record number of candidates for the International Qualifying Exam (IQE) - the three-part exam which tests the clinical skills and knowledge of dentists from overseas (non EEA) who wish to work in the UK. In 2006, 466 places for Part C (the third and final part of the exam) have been made available, compared to 109 in 2003.

Despite this, supply of exam places would still not meet demand in 2006, if such high numbers continue to join the exam list. This is largely due to the interest created by the active recruitment of dentists from overseas by the NHS over the last two years.

To allow existing candidates reasonable opportunity to sit the exam, the GDC has agreed to stop accepting new applications from prospective IQE candidates for a limited time, and admissions to the IQE list will be suspended from 10 April 2006.

By law, the IQE must be run by UK dental authorities. The dental schools are already coping with increased undergraduate numbers and could not reasonably commit to holding more IQE sittings. The GDC will continue to work with the dental schools to increase the number of Part C places available. However, it is unlikely that significant numbers of additional places will become available this year.

The situation will be closely monitored over the next couple of months and will be reviewed by the Council in October 2006. Hew Mathewson, president of the GDC, said it was a temporary measure and hoped to re-open the IQE list as soon as possible. All prospective candidates for the IQE have been advised to submit their application by the 10 April deadline. 


\section{Resolvin E1 protects against inflammation and bone loss}

To date, the prevention of gum disease is limited to successful oral hygiene and regular professional care. However, despite these preventive actions, plaque control is not enough to prevent disease in susceptible individuals with a high inflammatory response. Researchers from Goldman School of Dental Medicine, Department of Periodontology and Oral Biology, Boston University, presenting their findings at the 35th Annual Meeting of the American Association for Dental Research, introduced 'Resolvins', a new family of biologically active products of omega-3 fatty acids. They are natural endogenous regulators of the inflammatory response.

Since it is now known that inflammation plays a critical role in many diseases, including heart disease and asthma, experiments were carried out to test the actions of the newly described EPA (eicosapentanoic acid)-derived Resolvin E1 (RvE1) in regulating tissue destruction and resolving inflammation in gum disease. Experimental gum disease characterised by tissue inflammation and bone loss was stimulated in rabbits by the application of specific bacteria that cause human gum disease. The results of this study showed that topical application of RvE1 in experimental gum disease provided remarkable protection against soft tissue and bone loss associated with periodontitis. Analysis of these data supports the concept that inflammation is a good therapeutic target in the treatment of periodontal disease.

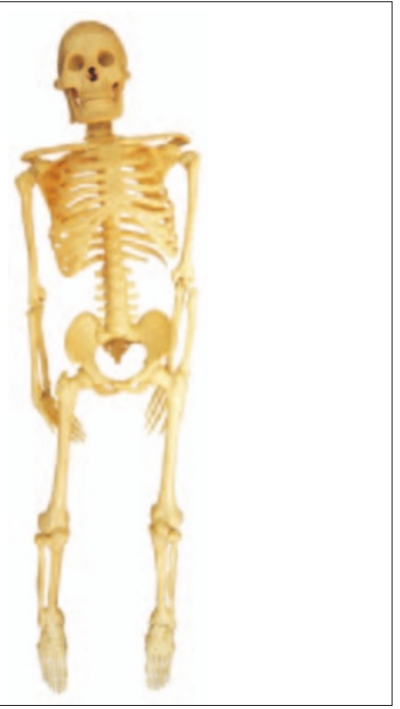

\section{Dentists sign up for Lakeland Challenge}

Two dentists are preparing to put their fitness to the test and raise at least $£ 4,400$ for disadvantaged children and young adults by taking part in England's longest, steepest and highest outdoor charity challenge. Mark Willings from Horbury, near Wakefield, and Richard Gray, who practices in Waterloo, near Huddersfield, are once again competing in the Ford Ranger Great Lakeland Challenge. The Challenge takes place in the Lake District on 19 May 2006. Mark will be joined by two other athletes and together they will canoe the length of Lake Windermere (10.5 miles), cycle 26 miles over Hard Knott and Wrynose - England's steepest passes - and then climb Scafell Pike (3,208 $\mathrm{ft}$ ), before finishing with an eight mile run into the Langdale Valley. Richard is their support driver and is responsible for getting his team-mates and their equipment to the right place for each leg of the Challenge.

The Ford Ranger Great Lakeland Challenge - which is organised by Wooden Spoon - has raised in excess of $£ 1$ million. Last year 33 teams generated a record £183,466. Wooden Spoon uses the money to benefit physically, mentally and socially disadvantaged children and young people. It currently supports 55 projects throughout the UK and Ireland. If you would like to help Mark and Richard fly the flag for the dental profession, please contact Mark Willings on 01924211234 to discuss sponsorship opportunities. Full details on the Ford Ranger Great Lakeland Challenge and entry forms are available from the Wooden Spoon Challenge Office on 01889582889.

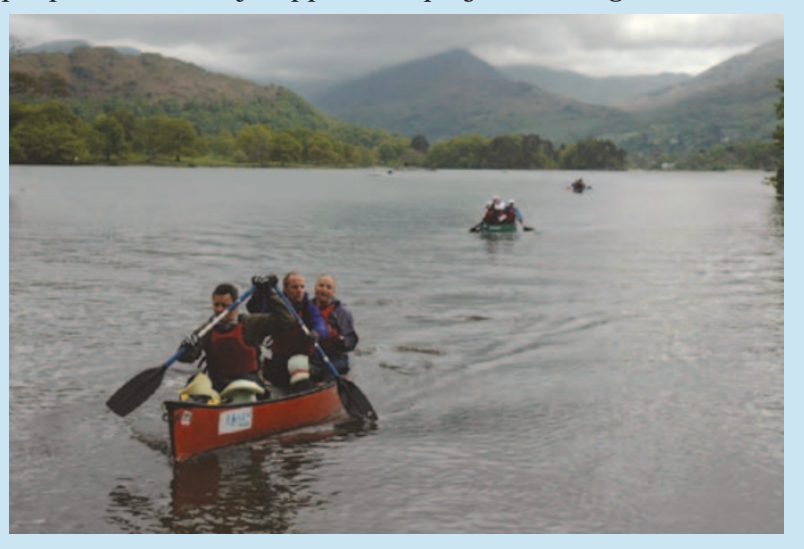

\section{Saliva component may predict future oral bone loss}

Researchers at the University at Buffalo have identified two components of saliva that may serve as the basis for novel tests to determine the risk for periodontal bone loss. By comparing dental x-rays of 100 patients with analyses of their saliva, the researchers found that higher-than-normal levels of a salivary protein called IL-1beta were associated with increased bone loss. The level of another protein, osteonectin, was inversely proportional to bone loss, suggesting this marker may serve as a measure of periodontal health.

Results of the research were presented at the annual meeting of the International Association of Dental Research on 10 March 2006. 'These results show that aboveaverage levels of IL- 1 beta in saliva may prove to help the dentist decide whether or not to treat the dental patient for periodontal disease,' said lead researcher Frank Scannapieco. 'Currently there is no early warning test for bone-loss activity. We can measure gum pocket depth, or the amount of bone remaining on an x-ray, but these methods only tell us how much damage already has been done.' Scannapieco said that if these

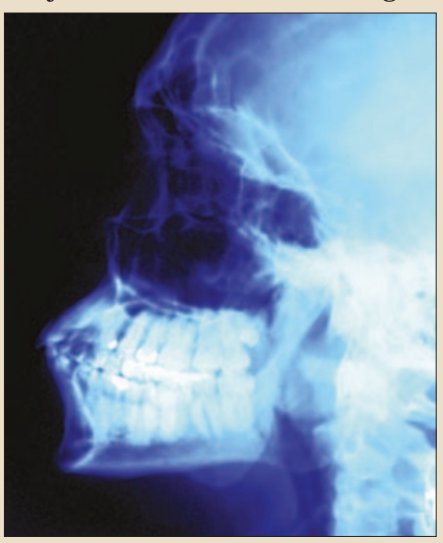
findings hold up in future longitudinal studies, dentists could use the test to decide what interventions are needed for the patient, and perhaps the frequency for recall visits. It could provide a quick and easy way to monitor patients over the long-term and to determine if a particular treatment is working. Previous studies had identified specific protein biomarkers of bone destruction in fluid collected from gum crevices in patients with active periodontal disease, but collecting enough of this fluid for analysis can be tedious and time consuming, whereas saliva is plentiful and easily collected. The research team now is performing follow-up studies to determine the validity of their results. 


\section{Dental treatment on the NHS could become more difficult}

Research conducted by the BBC suggests that getting dental treatment on the NHS may become even more difficult because of the new contract. Of the 300 dentists who replied to the World at One poll, a quarter said they would not sign up to the new contract. The BBC said that if the results were replicated across the country, it would mean that over 137,000 patients might have to go private, or find another NHS dentist. The survey also found that although half the dentists said they would sign, they would do so with 'deep misgivings about the future.'

A practice manager in Swindon told the BBC: 'It is my belief that the government are trying to do away altogether with NHS dental care but rather than admit to this, they are making it look like the dentist is wishing to go private by choice due to financial gain. We have the ability and capability to take on at least 10,000 more NHS patients, but are unable to do so because there is no funding.

\section{Oldest recorded case of impacted wisdom teeth}

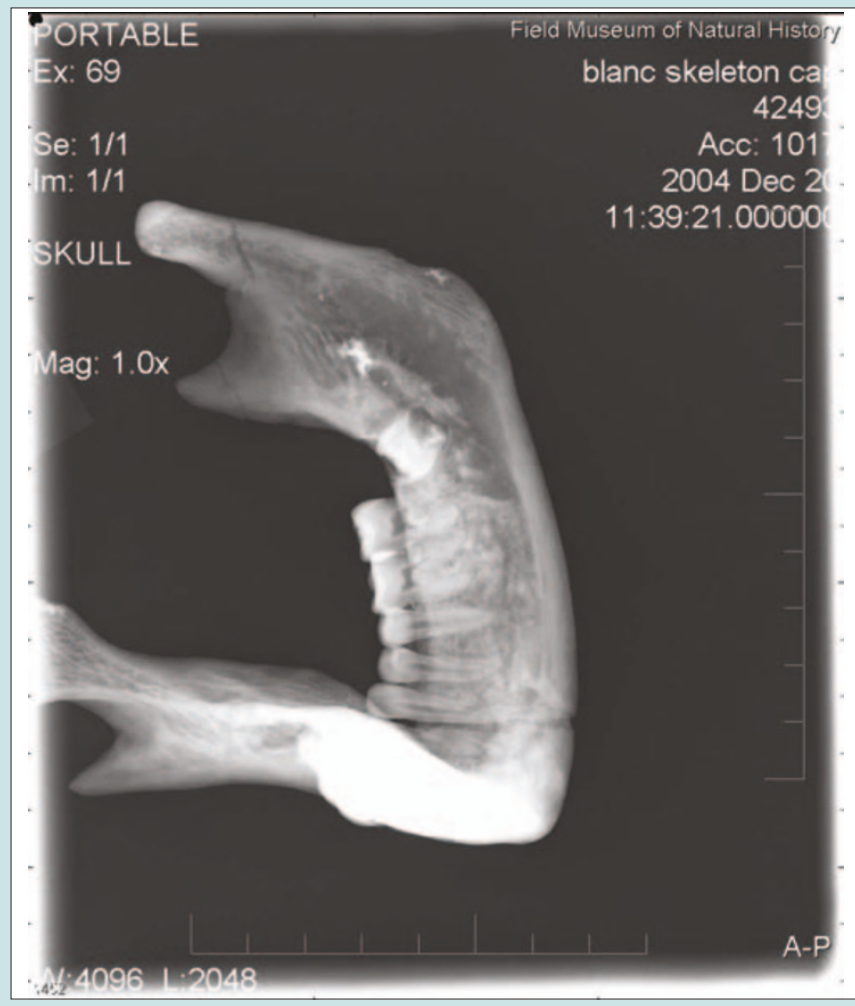

The earliest recorded case of impacted wisdom teeth belongs to the Magdalenian Girl, a nearly complete 13,000 - to 15,000 year-old skeleton excavated in France in 1911 and acquired by The Field Museum in 1926.

For years this rare, early anatomically modern human skeleton was thought to be that of a girl because her wisdom teeth had not erupted, an event that typically occurs between 18 and 22 years of age. New analysis of Magdalenian Girl's bones, however, has lead Field Museum scientists to conclude that she was not a girl but actually a 25- to 35-year-old woman at the time of her death.

Examination of new high-quality digital radiographs revealed that the wisdom teeth were, in fact, impacted, and had thus failed to erupt at the normal time. This is significant because impacted wisdom teeth are thought to be the result of dietary changes associated with later developments in human cultures. Impaction was unknown during the stone ages, scientists say, due to the coarse diet of the period.

This coarse diet would have required more chewing and higher bite forces, which could have stimulated growth of the jawbone and thereby created more room for the wisdom teeth to erupt. 'Finding impacted wisdom teeth 15,000 years ago indicates that the human diet might have already changed, some would say deteriorated, earlier than previously thought,' said Robert D. Martin, Field Museum provost and primatologist. 